\title{
Predictors of stillbirths and neonatal deaths in rural western Uganda
}

\author{
Cheryl A. Moyer ${ }^{\mathrm{a}, *}$, Candace K. Kolars ${ }^{\mathrm{b}}$, Samuel A. Oppong ${ }^{\mathrm{c}}$, Ashura Bakari ${ }^{\mathrm{d}}$, April Bell ${ }^{\mathrm{e}}$, Priscilla Busingye ${ }^{\mathrm{f}}$ \\ a Global REACH and Departments of Learning Health Sciences and Obstetrics and Gynecology, University of Michigan Medical School, Ann Arbor, MI, USA \\ b Office of Performance Assessment and Clinical Effectiveness, University of Michigan Health System, Ann Arbor, MI, USA \\ c Department of Obstetrics and Gynecology, Korle Bu Teaching Hospital, Accra, Ghana \\ d Ghana Health Service, Kumasi, Ghana \\ e School of Public Health, University of Michigan, Ann Arbor, MI, USA \\ ${ }^{\mathrm{f}}$ Department of Obstetrics and Gynecology, Virika Hospital, Fort Portal, Uganda
}

\section{A R T I C L E I N F O}

\section{Article history:}

Received 3 September 2015

Received in revised form 4 January 2016

Accepted 6 April 2016

\section{Keywords:}

Complications

Neonatal death

Pregnancy outcomes

Stillbirth

Sub-Saharan Africa

\begin{abstract}
A B S T R A C T
Objective: To explore pregnancy outcomes at a referral hospital in rural western Uganda. Methods: A retrospective study was undertaken using data for all deliveries at Virika Hospital, Fort Portal, Uganda, between July 1, 2009, and October 22, 2011. A detailed review of delivery logs was conducted. Categories were created for obstetric risk factors (e.g. grand multipara, history of hypertension), maternal delivery complications (e.g. eclampsia, hemorrhage), and neonatal complications (e.g. fetal distress, birth defects). Results: Overall, 4883 deliveries were included. Of the 517 neonates who did not survive, 430 (83.2\%) had been stillborn. After controlling for parity, gestational age, obstetric risk factors, and neonatal complications, risk factors for stillbirth included maternal delivery complications (risk ratio [RR] 3.32, 95\% confidence interval $[\mathrm{CI}] 2.34-4.71 ; P<0.001$ ) and living 51-100 km from the hospital (RR 3.37, 95\% CI 2.41-4.74; $P<0.001$ ). Risk factors for neonatal death included neonatal complications ( RR 5.79, 95\% CI 2.49-13.46; $P=0.001)$ and maternal delivery complications $(\mathrm{RR} 3.17,95 \% \mathrm{CI}$ 1.47-6.82; $P=0.003)$. Conclusion: Qualified providers need to be deployed to rural areas of Uganda to facilitate the prompt identification and management of pregnancy, delivery, and neonatal complications.

(C) 2016 International Federation of Gynecology and Obstetrics. Published by Elsevier Ireland Ltd. All rights reserved.
\end{abstract}

\section{Introduction}

Worldwide, approximately 6 million stillbirths and neonatal deaths occur annually [1,2], with the vast majority in low-income countries [2]. Although stillbirths and neonatal deaths are multifactorial in their cause, both are disproportionately influenced by the care received during labor and delivery [3]. According to certain estimates [4], nearly half of global stillbirths occur during labor.

In Uganda, an estimated 40000 stillbirths occur annually-the 10th highest stillbirth rate worldwide [4]. In 2011, the perinatal mortality rate (stillbirths and neonatal mortality combined) in Uganda was 40 per 1000 live births [5]. However, stillbirths and neonatal mortality are often not reported or captured in areas with weak vital registration systems, and therefore the burden of perinatal mortality is likely to be largely underestimated.

In rural western Uganda, where the total fertility rate is 6.4, more than $13 \%$ of women aged $15-49$ years are pregnant at any given time, and the mean number of children born to women aged $40-49$ years is 7.4 [5]. Pregnancy-related complications are often the norm rather than the exception. The 2011 Uganda Demographic Health Survey [5] showed that, among women with a delivery in the past 5 years who

\footnotetext{
* Corresponding author at: 220 Victor Vaughn Bldg, 1111 East Catherine Street, Ann Arbor, MI 48109-2054, USA. Tel.: + 1734615 2838; fax: +1 7316156300 .

E-mail address: camoyer@umich.edu (C.A. Moyer).
}

attended any prenatal care, $61 \%$ had been diagnosed with some type of pregnancy complication. In such settings, it is important to understand the magnitude of the problem, as well as to identify the factors most strongly associated with stillbirth and neonatal death to ensure appropriately targeted interventions. Thus, the present study was conducted to explore pregnancy outcomes at one large referral hospital in rural western Uganda.

\section{Materials and methods}

A retrospective study was undertaken of all deliveries at Virika Hospital, Fort Portal, Uganda, between July 1, 2009, and October 22, 2011. There were no exclusion criteria; if the delivery was recorded in the hospital log book, it was entered into the study record. This research was reviewed and approved by the Institutional Review Board at the University of Michigan, as well as by management at Virika Hospital. Informed consent was not required given the anonymous, retrospective nature of data collection.

Virika Hospital is a Catholic hospital with 205 beds that serves as a rural referral center for more than 10 districts in southwestern Uganda. Situated in rural Kabarole district (population approximately 360 000), Virika Hospital is home to one of only four practicing obstetrician-gynecologists in the Western region of Uganda. In this region, $55.9 \%$ of women who delivered within the 5 years before 2011 reported using a facility for their most recent delivery [5]. Approximately 
2000 deliveries occur at the hospital per year, with one-quarter having been referred from elsewhere [6].

Data were collected from hospital registration books, which are overseen by the head physician and routinely reviewed for completeness. Information about admissions, maternal and neonatal characteristics, and deliveries had been recorded by the nursing staff or the attending physician. Data were recorded at the time of hospital discharge, typically within 1 day of delivery.

Trained research assistants entered the data into an Excel 2010 spreadsheet (Microsoft Corporation, Redmond, WA, USA), removing any information identifying either the mother or the neonate(s). A $10 \%$ subsample of data was identified and double-checked for quality control. If multiple errors were found, the data included in the specific page of the registration book was re-entered.

Delivery outcomes were categorized as live birth or stillbirth, with further subcategorization of stillbirth as fresh (skin still intact, appearance suggesting intrapartum death within previous 8-12 hours) or macerated (skin and soft tissue changes, including redness, peeling, or breakdown, suggesting death well before delivery) [7]. Deaths of neonates occurring before hospital discharge were categorized as neonatal deaths. These variables were combined to yield four possible outcomes: live birth (survived to discharge), fresh stillbirth, macerated stillbirth, and neonatal death.

Documented risk factors and complications were categorized as history of obstetric risk factors (including previous cesarean delivery), grand multiparity, or history of hypertension or pre-eclampsia during pregnancy. Maternal delivery complications included premature rupture of membranes, prepartum hemorrhage, cephalopelvic disproportion, eclampsia, impending uterine rupture, uterine rupture, postpartum hemorrhage, or retained second twin. Neonatal complications included fetal distress, umbilical cord wrapped around the neck, birth asphyxia, or birth defects.

Distance to facility was estimated by comparing the mother's district of origin to a map of Uganda and categorizing the districts as closest to Virika (<50 km; Kabarole), within 50-100 km (Kyenjojo, Bundibugyo, Ntoroko, Kamwenge, Kasese), and further than $100 \mathrm{~km}$ away (Mbarara, Kanungu, Mubende, Kyegegwa, Kibaale) (Fig. 1). This categorization, although not accounting for exact distances within each district, was

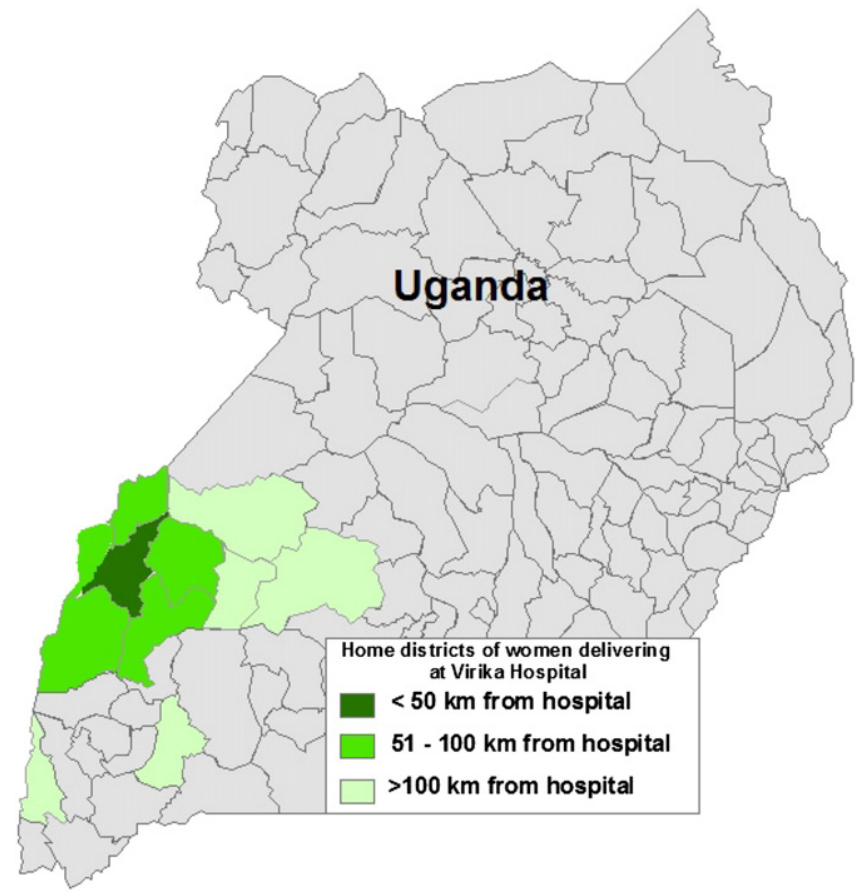

Fig. 1. Districts in western Uganda from where women were referred to Virika Hospital. discussed and confirmed by Ugandan staff as the most appropriate categorization given that consistently recorded village data or coordinates of women's home villages were not available.

Data were cleaned, prepared for analysis, and entered into Stata 13.0 (StataCorp, College Station, TX, USA). Frequencies and descriptive statistics were calculated for key variables, including maternal age, parity, neonatal gestational age and birthweight, type of delivery, delivery outcome, and complications. $P<0.05$ was considered statistically significant.

\section{Results}

A total of 4883 births were recorded in the hospital birth registry during the relevant period. Table 1 illustrates the characteristics of the mothers and their neonates. The distance travelled to hospital was greater than $50 \mathrm{~km}$ for 1697 (36.1\%) of the 4696 births with information

Table 1

Characteristics of the births included ( $n=4883)$.

\begin{tabular}{|c|c|}
\hline Characteristic & Value $^{\mathrm{a}}$ \\
\hline \multicolumn{2}{|l|}{ Maternal } \\
\hline Age, y & $25.7 \pm 0.9(12-48)$ \\
\hline$<18$ & $712(14.6)$ \\
\hline $19-24$ & $1897(38.8)$ \\
\hline $25-34$ & $1739(35.6)$ \\
\hline$>35$ & $535(11.0)$ \\
\hline \multicolumn{2}{|l|}{ Parity } \\
\hline 1 & $73(1.5)$ \\
\hline $2-4$ & $1657(33.9)$ \\
\hline$\geq 5$ & $3153(64.6)$ \\
\hline \multicolumn{2}{|l|}{ Neonatal } \\
\hline \multicolumn{2}{|l|}{ Gestational age at birth, wk } \\
\hline$<28$ (spontaneous/induced abortion) & $18(0.4)$ \\
\hline $28-37$ (preterm) & $584(12.0)$ \\
\hline $37-42($ term $)$ & $3468(71.0)$ \\
\hline$>42$ (post-term) & $1(<0.1)$ \\
\hline No information available & $812(16.6)$ \\
\hline \multicolumn{2}{|l|}{ Birthweight, kg } \\
\hline$<1.5$ (very low birthweight) & $42(0.9)$ \\
\hline $1.5-2.5$ (low birthweight) & $451(9.2)$ \\
\hline 2.5-4.0 (normal birthweight) & $4079(83.5)$ \\
\hline$>4.0$ (macrosomia) & $311(6.4)$ \\
\hline \multicolumn{2}{|l|}{ Type of delivery } \\
\hline Vaginal & $3388(69.4)$ \\
\hline Cesarean & $1465(30.0)$ \\
\hline No information available & $30(0.6)$ \\
\hline \multicolumn{2}{|l|}{ Outcome at discharge } \\
\hline Neonate alive & $4366(89.4)$ \\
\hline Neonate dead & $517(10.6)$ \\
\hline Stillbirth & $430(83.2)$ \\
\hline Fresh stillbirth & $250(48.4)$ \\
\hline Macerated stillbirth & $170(32.9)$ \\
\hline Unclassified stillbirth & $10(1.9)$ \\
\hline Neonatal death & $87(16.8)$ \\
\hline Multiple pregnancy & $313(6.4)$ \\
\hline \multicolumn{2}{|l|}{ Fetal sex } \\
\hline Male & $2582(52.9)$ \\
\hline Female & $2198(45.0)$ \\
\hline No information available & $103(2.1)$ \\
\hline 1-min Apgar score $\leq 8$ & $1823(37.3)$ \\
\hline 5-min Apgar score $\leq 8$ & $724(14.8)$ \\
\hline Any obstetric risk factors & $383(7.8)$ \\
\hline Any maternal delivery complications & $938(19.2)$ \\
\hline Obstructed labor & $307(6.3)$ \\
\hline Any neonatal complications & $469(9.6)$ \\
\hline Fetal distress & $390(8.0)$ \\
\hline HIV-positive mother & $1353(27.7)$ \\
\hline Antiretroviral usage & $961(71.0)$ \\
\hline \multicolumn{2}{|l|}{ Distance to nearest hospital, km } \\
\hline$<50$ & $2999(61.4)$ \\
\hline $51-100$ & $1617(33.1)$ \\
\hline$>100$ & $80(1.6)$ \\
\hline No information available & $187(3.8)$ \\
\hline Any prenatal care & $3240(66.4)$ \\
\hline
\end{tabular}

a Values are given as mean \pm standard error (range) or number (percentage). 
on distance to facility. More than two-thirds of deliveries were vaginal births, and most neonates survived until discharge (Table 1). Of the 517 neonates who did not survive, most were stillbirths (Fig. 2).

Table 2 illustrates the results of bivariate multinomial logistic regression analyses, indicating the factors more likely to be associated with live birth, stillbirth, or neonatal death. The factors most strongly associated with stillbirth (compared with a live birth) were older maternal age and higher parity, lower neonatal gestational age and birthweight, no history of obstetric risk factors, maternal delivery complications, HIV-positive mother, no prenatal care, and the hospital being more than $50 \mathrm{~km}$ away from the mother's home ( $P \leq 0.004$ for all). The factors most strongly associated with neonatal death (compared with a live birth) were lower gestational age at birth, lower birthweight, male sex, maternal delivery complications, neonatal complications, HIVpositive mother, no prenatal care, and the hospital being $50-100 \mathrm{~km}$ away from home $(P \leq 0.04$ for all $)$. As expected, maternal age and parity were significantly correlated (Pearson $r=0.58, P<0.001$ ), as were neonatal birthweight and gestational age (Pearson $r=0.36, P<0.001$ ). As a result, maternal age and birthweight were dropped from multivariate models that included parity and gestational age, respectively.

Table 3 illustrates the risk ratios for stillbirth and neonatal death in a multivariate multinomial logistic regression model. Distance to the hospital (50-100 km) and maternal delivery complications were the factors most strongly associated with stillbirth, even after controlling for parity, gestational age, history of obstetric risk factors, and neonatal complications. Women with delivery complications were 3.3-fold more likely to have a stillborn neonate than were those without delivery complications. Women who lived 51-100 km from the hospital were 3.4-fold more likely to deliver a stillborn neonate than were those who lived within $50 \mathrm{~km}$ from the hospital. Aside from gestational age, neonatal complications and maternal delivery complications were the factors most strongly associated with neonatal death, even after controlling for parity, obstetric risk factors, and distance to the hospital. Deliveries during which neonatal complications occurred were 5.8-fold more likely to result in a neonatal death than were those without neonatal complications. Deliveries during which maternal complications occurred were 3.2-fold more likely to result in a neonatal death than were those without maternal complications.

\section{Discussion}

In the present study, more than one-third of women had to travel at least $50 \mathrm{~km}$ to reach the one referral hospital with a practicing obstetrician-gynecologist in a part of rural western Uganda. Among women whose delivery outcome was a stillbirth or neonatal death, one-third were classified as having macerated stillbirths, suggesting that death had occurred before hospital admission. The factors most strongly associated with stillbirth included distance to the hospital and presence of maternal delivery complications, whereas the factors most strongly associated with neonatal death were maternal delivery complications and neonatal complications.

These findings are similar to those of Nakimuli et al. [8], who reported that severe obstetric complications contribute significantly to stillbirths and neonatal deaths in Uganda. Nevertheless, these investigators focused on cases with severe pregnancy and childbirth complications [8], whereas the present study included all women delivering at one hospital in a 3-year period. The present findings re-emphasize the critical importance of identifying and managing pregnancy, delivery, and neonatal complications in a timely manner to improve pregnancy outcomes.

A previous study on neonatal outcomes in Uganda conducted in a neonatal intensive care unit found that mortality was inversely proportional to neonatal birthweight and gestational age [9], which is consistent with the present findings. Additionally, in the present study, although both birthweight and gestational age were significantly associated with neonatal death, their contribution was not as large as the presence of additional maternal or neonatal complications.

The present study has several notable strengths, including the exceptionally detailed record-keeping overseen by P.B., spanning 28 months of deliveries. All data were entered into one hand-written delivery ledger, which was reviewed periodically to ensure consistency in categorization and notation. Data were summarized monthly on site, with monthly tallies included in the ledger. Monthly summaries were compared with the findings obtained once data were transferred into a computerized record, allowing for independent data checking for accuracy. Such attention to data collection in a busy rural hospital is extremely rare, and the inclusion of detailed assessment of stillbirths is rarer still, providing a degree of confidence in the findings that is unusual for such a setting.

Nevertheless, several limitations must be mentioned. Despite the consistent presence of and oversight by one of the authors, challenges in data collection and coding in such a setting are inevitable. For example, it is possible that pregnancy-related complications were not identified or that some neonatal deaths could have been misclassified as stillbirths. It is also difficult to truly disaggregate the effect of prematurity, given its relationship with several variables, including neonatal birthweight and maternal (premature rupture of membranes) and neonatal (asphyxia) complications. Furthermore, it should be considered that things have changed in Uganda since these data were collected. Finally, the data are limited to what was observed or recorded while women were within the hospital-no follow-up data are available regarding the fate of neonates after discharge. Given that most women were discharged within 1 day of delivery, and that many neonatal deaths occur within the first week after delivery, it is likely that neonatal mortality was underestimated in the present study.

The present findings have several critical implications. First, it is clear that women are traveling extremely long distances to obtain high-quality care from a trained obstetrician-gynecologist. Policy efforts to improve access to high-quality care in remote locations must

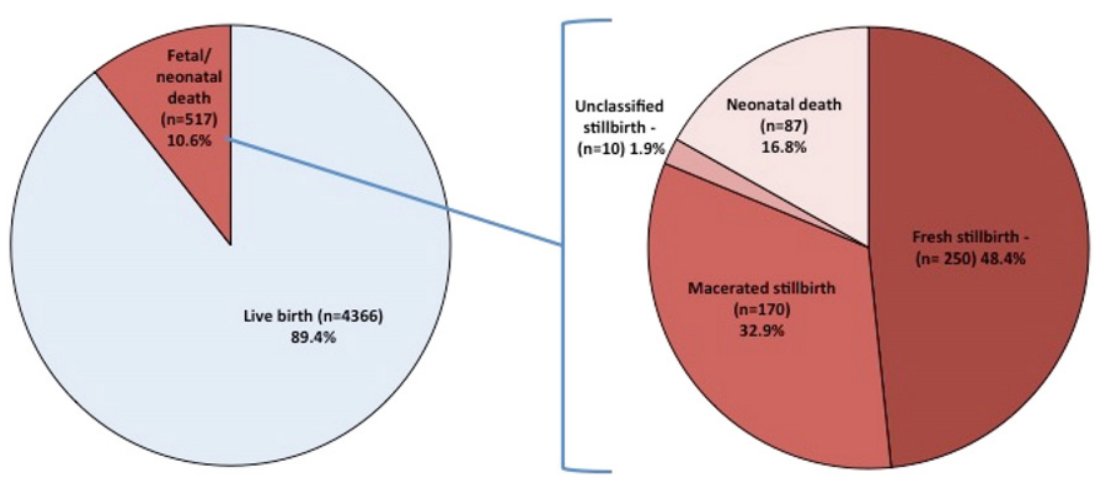

Fig. 2. Pregnancy outcomes. 
Table 2

Bivariate multinomial logistic regression indicating factors associated with stillbirths and neonatal deaths. ${ }^{\mathrm{a}}$

\begin{tabular}{|c|c|c|c|c|c|}
\hline \multirow[t]{2}{*}{ Variable } & \multirow[t]{2}{*}{ Live birth $(\mathrm{n}=4366)^{\mathrm{b}}$} & \multirow[t]{2}{*}{ Stillbirth $(n=430)$} & \multirow[t]{2}{*}{ Neonatal death $(\mathrm{n}=87)$} & \multicolumn{2}{|l|}{$P$ value $^{\mathrm{c}}$} \\
\hline & & & & Stillbirth vs live birth & Neonatal death vs live birth \\
\hline Maternal age, $\mathrm{y}$ & $24.6(24.4-24.8)$ & $25.9(25.2-26.5)$ & $23.8(22.5-25.2)$ & $<0.001$ & 0.24 \\
\hline Maternal parity & $3.9(3.8-4.0)$ & $4.7(4.4-5.0)$ & $4.0(3.3-4.6)$ & $<0.001$ & 0.77 \\
\hline Gestational age at birth, wk & $37.7(37.6-37.8)$ & $36.1(35.8-36.5)$ & $36.3(35.4-37.2)$ & $<0.001$ & $<0.001$ \\
\hline Birthweight, kg & $3.1(3.08-3.11)$ & $2.9(2.7-2.9)$ & $2.6(2.4-2.9)$ & $<0.001$ & $<0.001$ \\
\hline Vaginal delivery & $3045(69.7)$ & $286(66.5)$ & $54(62.1)$ & 0.58 & 0.15 \\
\hline Cesarean delivery & $1301(29.8)$ & $130(30.2)$ & $32(36.8)$ & 0.58 & 0.15 \\
\hline Male fetal sex & $2304(52.8)$ & $221(51.4)$ & $56(64.4)$ & 0.97 & 0.04 \\
\hline Any obstetric risk factors & $358(8.2)$ & $18(4.2)$ & $7(8.0)$ & 0.004 & 0.96 \\
\hline Any maternal delivery complications & $756(17.3)$ & $151(35.1)$ & $29(33.3)$ & $<0.001$ & $<0.001$ \\
\hline Any neonatal complications & $406(9.3)$ & $32(7.4)$ & $30(34.5)$ & 0.203 & $<0.001$ \\
\hline HIV-positive mother & $1158(26,5)$ & $164(38.1)$ & $31(35.6)$ & $<0.001$ & 0.02 \\
\hline Any prenatal care received & $2983(68.3)$ & $208(48.4)$ & $42(48.3)$ & $<0.001$ & 0.016 \\
\hline Hospital > $100 \mathrm{~km}$ from home & $70(1.6)$ & $9(2.1)$ & $1(1.1)$ & 0.036 & 0.92 \\
\hline Hospital $50-100 \mathrm{~km}$ from home & $1330(30.5)$ & $234(54.4)$ & $46(52.9)$ & $<0.001$ & $<0.001$ \\
\hline
\end{tabular}

a Values are given as mean (range) or number (percentage), unless indicated otherwise.

b Survived to discharge.

c Bivariate multinomial logistic regression.

Table 3

Risk ratios calculated through multinomial logistic regression with live birth as the base outcome.

\begin{tabular}{|c|c|c|c|c|}
\hline & \multicolumn{2}{|l|}{ Stillbirths } & \multicolumn{2}{|l|}{ Neonatal deaths } \\
\hline & $\begin{array}{l}\text { Risk ratio } \\
(95 \% \mathrm{CI})\end{array}$ & $\begin{array}{l}P \\
\text { value }\end{array}$ & $\begin{array}{l}\text { Risk ratio } \\
(95 \% \mathrm{CI})\end{array}$ & $\begin{array}{l}P \\
\text { value }\end{array}$ \\
\hline Parity & $1.13(1.06-1.21)$ & $<0.001$ & $0.99(0.85-1.17)$ & 0.985 \\
\hline Gestational age & $0.71(0.66-0.76)$ & $<0.001$ & $0.65(0.59-0.72)$ & $<0.001$ \\
\hline Any obstetric risk factors & $0.33(0.16-0.67)$ & 0.003 & $1.14(0.40-3.23)$ & 0.803 \\
\hline $\begin{array}{l}\text { Any maternal delivery } \\
\text { complications }\end{array}$ & $3.32(2.34-4.71)$ & $<0.001$ & $3.17(1.47-6.82)$ & 0.003 \\
\hline $\begin{array}{l}\text { Any neonatal } \\
\text { complications }\end{array}$ & $0.95(0.52-1.70)$ & 0.852 & $5.79(2.49-13.46)$ & 0.001 \\
\hline \multicolumn{5}{|l|}{ Distance to hospital, $\mathrm{km}^{\mathrm{a}}$} \\
\hline $51-100$ & $3.37(2.41-4.71)$ & $<0.001$ & $1.96(0.94-4.08)$ & 0.072 \\
\hline$>100$ & $2.76(0.77-9.78)$ & 0.116 & $4.51(0.53-38.2)$ & 0.167 \\
\hline
\end{tabular}

Abbreviation: $\mathrm{CI}$, confidence interval.

a Reference: $<50 \mathrm{~km}$.

be coupled with recruitment and retention incentives to encourage providers to relocate to rural areas. Second, the prompt identification and effective management of complications during pregnancy, delivery, and the immediate postpartum period remain high priorities if stillbirth and neonatal mortality rates are to be curbed. Although such a statement is no surprise to practicing clinicians and dovetails well with the most recent Lancet child survival series [10-12], the implication for policymakers is paramount: women need education regarding when to seek care, communities need to understand the importance of early treatment and support women in obtaining it, and providers need sufficient resources, training, and ongoing support to be able to provide high-quality care at any hour.

\section{Acknowledgments}

Financial support was provided by Global REACH at the University of Michigan, which allowed for manual data entry from the Virika Hospital birth registry.

\section{Conflict of interest}

The authors have no conflicts of interest.

\section{References}

[1] Lawn JE, Blencowe H, Oza S, You D, Lee AC, Waiswa P, et al. Every Newborn: progress, priorities, and potential beyond survival. Lancet 2014;384(9938): 189-205.

[2] United Nations Children's Fund, World Health Organization, World Bank, United Nations Department of Economic and Social Affairs Population Division. Levels and trends in child mortality: report 2013. New York, NY: United Nations Children's Fund; 2013.

[3] Lawn JE, Cousens S, Zupan J. for the Lancet Neonatal Survival Steering Team. 4 million neonatal deaths: When? Where? Why? Lancet 2005;365(9462):891-900.

[4] Kiguli J, Namusoko S, Kerber K, Peterson S, Waiswa P. Weeping in silence: community experiences of stillbirths in rural eastern Uganda. Glob Health Action 2015;8:24011.

[5] Uganda Bureau of Statistics and ICF International Inc. Uganda Demographic and Health Survey 2011. Kampala and Calverton, MA: UBOS and ICF International Inc.; 2012.

[6] Moyer CA, Kolars C, Busingye P. Three years of data on the impact of obstetrician/ gynecologist coverage in rural Uganda. Int J Gynecol Obstet 2014;126(3):284-5.

[7] Gold KJ, Abdul-Mumin AS, Boggs ME, Opare-Addo HS, Lieberman RW. Assessment of "fresh" versus "macerated" as accurate markers of time since intrauterine fetal demise in low-income countries. Int J Gynecol Obstet 2014;125(3):223-7.

[8] Nakimuli A, Mbalinda SN, Nabirye RC, Kakaire O, Nakubulwa S, Osinde MO, et al. Still births, neonatal deaths and neonatal near miss cases attributable to severe obstetric complications: a prospective cohort study in two referral hospitals in Uganda. BMC Pediatr 2015;15:44.

[9] Hedstrom A, Ryman T, Otai C, Nyonyintono J, McAdams RM, Lester D, et al. Demographics, clinical characteristics and neonatal outcomes in a rural Ugandan NICU. BMC Pregnancy Childbirth 2014;14:327.

[10] Bryce J, Victoria CG, Black RE. The unfinished agenda in child survival. Lancet 2013; 382(9897):1049-59.

[11] Bhutta ZA, Das JK, Bahl R, Lawn JE, Salam RA, Paul VK, et al. Can available interventions end preventable deaths in mothers, newborn babies, and stillbirths, and at what cost? Lancet 2014;384(9940):347-70.

[12] Dickson KE, Simen-Kapeu A, Kinney MV, Huicho L, Vesel L, Lackritz E, et al. Every Newborn: health-systems bottlenecks and strategies to accelerate scale-up in countries. Lancet 2014;384(9941):438-54. 